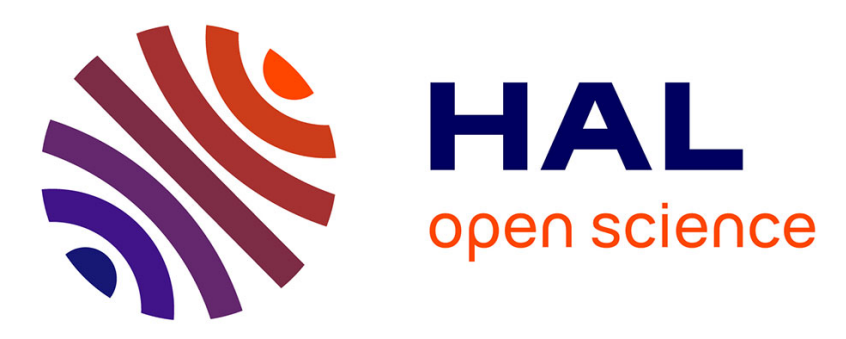

\title{
Simplified modelling strategies for reinforced concrete structures
}

Panagiotis Kotronis, Stéphane Grange

\section{To cite this version:}

Panagiotis Kotronis, Stéphane Grange. Simplified modelling strategies for reinforced concrete structures. European Journal of Environmental and Civil Engineering, 2010, 14 (6-7), pp.823-838. 10.1080/19648189.2010.9693264. hal-01007300

\section{HAL Id: hal-01007300 https://hal.science/hal-01007300}

Submitted on 11 Nov 2019

HAL is a multi-disciplinary open access archive for the deposit and dissemination of scientific research documents, whether they are published or not. The documents may come from teaching and research institutions in France or abroad, or from public or private research centers.
L'archive ouverte pluridisciplinaire HAL, est destinée au dépôt et à la diffusion de documents scientifiques de niveau recherche, publiés ou non, émanant des établissements d'enseignement et de recherche français ou étrangers, des laboratoires publics ou privés. 


\section{Simplified modelling strategies for reinforced concrete structures}

\section{Panagiotis Kotronis* — Stéphane Grange**}

* Research Institute of Civil Engineering and Mechanics (GeM)

UMR CNRS 6183, Ecole Centrale de Nantes

1, rue de la Noë, BP 92101, F-44321 Nantes cedex 3

Panagiotis.Kotronis@ec-nantes.fr

** Laboratoire Sols Solides Structures et Risques (3S-R)

UJF/INPG/CNRS UMR 5521

Domaine Universitaire

BP 53, F-38041 Grenoble cedex 9

Stephane.Grange@hmg.inpg.fr

ABSTRACT. Three simplified modelling strategies are proposed to simulate the non linear behaviour of reinforced concrete $(R C)$ structures submitted to severe loadings. The Equivalent Reinforced Concrete model (ERC) is suitable for very squat $R C$ walls and it is based on the Framework method coupled with damage mechanics and plasticity constitutive laws. The multifiber Timoshenko beam can be used for slender or squat structures submitted to severe shear or torsion. Finally, the SSI macro-element coupled with the multifiber beam is able to reproduce soil structure interaction phenomena on the foundation and the structure.

RÉSUMÉ. Trois stratégies simplifiées de modélisation du comportement non linéaire de structures en béton armé soumises à des chargements sévères sont proposées. Le béton armé équivalent est adéquat pour des voiles très faiblement élancés. Il est inspiré de la Framework method couplée avec des lois de comportement basées sur la mécanique de l'endommagement et de plasticité. La poutre multifibre Timoshenko est utilisée pour des structures élancées ou à faible élancement soumises à du cisaillement ou de la torsion. Enfin, le macro-élément ISS couplé avec la poutre multifibre est capable de reproduire les phénomènes d'interaction sol/structure au niveau de la fondation et de la structure.

KEYWORDS: SSI, Timoshenko beam, multifiber beam, shear, torsion, macro-element. MOTS-CLÉS : ISS, poutre Timoshenko, poutre multifibre, cisaillement, torsion, macro-élément. 


\section{Introduction}

Non-linear dynamic analysis based on detailed finite element models requires large-scale computations and delicate solution techniques. The necessity to perform parametric studies and the stochastic nature of the input accelerations often impose simplified numerical modelling in order to reduce computational cost. Three recently developed simplified modelling strategies are presented hereafter together with some validation examples:

- The Equivalent Reinforced Concrete model (ERC), suitable to reproduce the global (force/displacement) behaviour of squat reinforced concrete walls.

- A multifiber Timoshenko beam element, capable to simulate the non linear behaviour of reinforced concrete (RC) structures submitted to bending, shear and torsion.

- A macro-element that, coupled with multifiber beams, is able to reproduce complicate Soil Structure Interaction phenomena.

All the above tools can be introduced in every general purpose finite element code and could be of great importance in the everyday life of an engineering office.

\section{Equivalent Reinforced Concrete model}

A model based on first order beam theory (Bernoulli or Timoshenko) is unable to reproduce shear deformations and stresses in structures presenting a very small slenderness ratio (Mazars et al., 2002). An alternative simplified method is the so called Equivalent Reinforced Concrete model (ERC), (Kotronis, 2000), (Mazars et al., 2002), (Kotronis et al., 2003). The model uses a lattice mesh and it is inspired on the Framework Method (Hrennikoff, 1941). The basic idea consists on using the patterns of the Framework Method in a non-linear context and for a non-homogenous material with constitutive laws based on damage mechanics and plasticity. The main assumptions of the proposed strategy are (Figure 1):

1) An elementary volume of reinforced concrete $(\mathrm{EV})$ is separated into a concrete element (C) and a horizontal and a vertical reinforcement bar $\left(S_{H}\right.$ and $S_{V}$ respectively). Concrete and steel are then modelled separately using two different lattices.

2) The sections of the bars simulating concrete are derived from the Framework Method. 1D damage mechanics constitutive laws are introduced.

3) A lattice composed by horizontal and vertical bars coupled with a uniaxial plasticity model simulates steel. The section and position of the bars coincide with the actual section and position of the reinforcement. Therefore, the lattice used for steel is in general different from the lattice simulating concrete. In order to simplify the mesh the method of distribution can also be used, where the sections of bars are defined proportional to a corresponding surface area, see Figure 6. More information and different case studies can be found in (Kotronis, 2000), (Mazars et al., 2002), (Kotronis et al., 2003). 
4) Perfect bond is assumed between concrete and steel.

5) When the stress field is quite homogeneous, the number of elements that simulate concrete or steel does not have a great influence on the results (Kotronis, 2000). Therefore a "macroscopic" model can be used instead of the "equivalent lattice", see Figure 1.

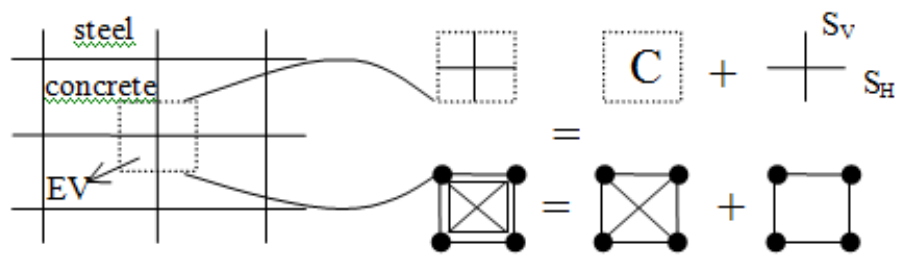

Elementary Volume

Equiv. lattice Concrete Steel

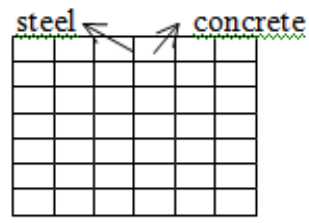

Cont medium

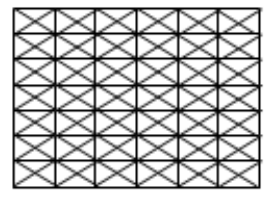

Equivalent lattice

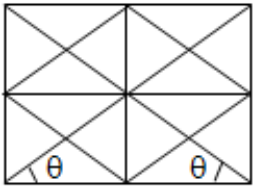

Macroscopic model

Figure 1. The Equivalent Reinforced Concrete model

For plane stress conditions and for the concrete lattice, the pattern presented in Figure 2 and the following equations of the Framework Method can be used.

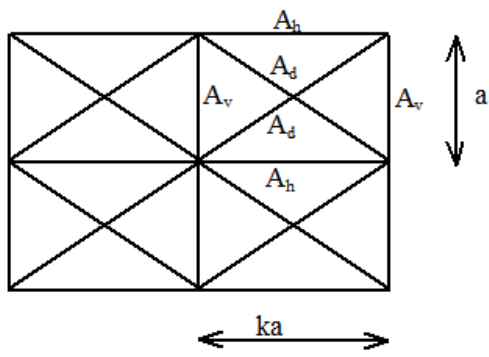

$>$ The ratio height/length is arbitrary.

Equations are valid for a Poisson's ratio equal to $1 / 3$.

$A_{h}, A_{v}, A_{d}:$ Section of bars

Figure 2. Framework Method - Pattern for plane stress

$$
A_{\mathrm{v}}=\frac{3}{8} \frac{3 k^{2}-1}{k} \alpha t
$$




$$
\begin{aligned}
& A_{\mathrm{h}}=\frac{3}{8}\left(3-k^{2}\right) \alpha t \\
& A_{\mathrm{d}}=\frac{3}{16} \frac{\left(1+k^{2}\right)^{\frac{3}{2}}}{k} \alpha t,
\end{aligned}
$$

where $\mathrm{k}$ the ratio between the length and the height $\alpha$ of the pattern and $\mathrm{t}$ the width of the plate.

\section{REMARKS.}

1) In order to derive the previous pattern, the criterion of suitability adopted by Hrennikoff is the equality in deformability of the framework and the solid material in elasticity. In other words, the pattern gives the exact results only for an elastic homogeneous material.

2) More complicate pattens of the Framework method are independent of the Poisson ratio. We choose to work with the simplest one in order to decrease the necessary computational time.

3) A crucial parameter for the success of the non-linear simulation is the angle $\theta$ that the diagonals of the concrete lattice form with the horizontal bars. This angle depends on the reinforcement ratios in the horizontal and vertical direction, the loading (normal compressive stress at the base of the specimens and shear stress) and the boundary conditions. It is related with the direction of the cracks into the structure (the bars are supposed reproducing the Ritter-Mörsch scheme). Calibrating this angle by performing an elastic calculation to get the orientation of the principal axis when cracking begins is a way to obtain roughly a solution. However, sensitivity increases with low reinforcement ratios and so the question is still open, see (Kotronis et al., 2003) and Subsection 5.1.2).

\section{Multifiber Timoshenko beam}

A 3D multifiber Timoshenko beam element has been developed in (Kotronis, 2000), (Kotronis et al., 2004), (Kotronis et al., 2005a) and (Mazars et al., 2006). The element is displacement-based and has higher order interpolation functions to avoid any shear locking phenomena (cubic and quadratic polynomials are used for the transverse and rotational displacements respectively (Friedman et al., 1993)).

In the following equations 1 and 2 are the two nodes of the beam, $x$ its axis, $s$ the subscript defining the "section variables", $u, v, w$ the displacements and $\theta_{x}, \theta_{y}, \theta_{z}$ the rotations according to the $x, y, z$ axis respectively. $L$ is the length, $S$ the section, $\kappa_{y}, \kappa_{z}$ the shear correction factors, $I$ the moment of inertia, $E$ the Young and $G$ the shear moduli, Figure 3. 
The matrix $\underline{\underline{N}}$ containing the interpolation functions takes the following form:

$$
\underline{\underline{N}}=\left[\begin{array}{cccccccccccc}
N_{1} & 0 & 0 & 0 & 0 & 0 & N_{2} & 0 & 0 & 0 & 0 & 0 \\
0 & N_{3} & 0 & 0 & 0 & N_{4} & 0 & N_{5} & 0 & 0 & 0 & N_{6} \\
0 & 0 & N_{3}^{*} & 0 & -N_{4}^{*} & 0 & 0 & 0 & N_{5}^{*} & 0 & -N_{6}^{*} & 0 \\
0 & 0 & 0 & N_{1} & 0 & 0 & 0 & 0 & 0 & N_{2} & 0 & 0 \\
0 & 0 & -N_{7}^{*} & 0 & N_{8}^{*} & 0 & 0 & 0 & -N_{9}^{*} & 0 & N_{10}^{*} & 0 \\
0 & N_{7} & 0 & 0 & 0 & N_{8} & 0 & N_{9} & 0 & 0 & 0 & N_{10}
\end{array}\right]
$$

$$
\begin{aligned}
\mathrm{N}_{1} & =1-\frac{x}{L} \\
\mathrm{~N}_{2} & =\frac{x}{L} \\
\mathrm{~N}_{3} & =\frac{1}{1+\phi}\left\{2\left(\frac{x}{L}\right)^{3}-3\left(\frac{x}{L}\right)^{2}-\phi\left(\frac{x}{L}\right)+1+\phi\right\} \\
\mathrm{N}_{4} & =\frac{L}{1+\phi}\left\{\left(\frac{x}{L}\right)^{3}-\left(2+\frac{\phi}{2}\right)\left(\frac{x}{L}\right)^{2}+\left(1+\frac{\phi}{2}\right)\left(\frac{x}{L}\right)\right\} \\
\mathrm{N}_{5} & =\frac{-1}{1+\phi}\left\{2\left(\frac{x}{L}\right)^{3}-3\left(\frac{x}{L}\right)^{2}-\phi\left(\frac{x}{L}\right)\right\} \\
\mathrm{N}_{6} & =\frac{L}{1+\phi}\left\{\left(\frac{x}{L}\right)^{3}-\left(1-\frac{\phi}{2}\right)\left(\frac{x}{L}\right)^{2}-\frac{\phi}{2}\left(\frac{x}{L}\right)\right\} \\
\mathrm{N}_{7} & =\frac{6}{(1+\phi) L}\left\{\left(\frac{x}{L}\right)^{2}-\left(\frac{x}{L}\right)\right\} \\
\mathrm{N}_{8} & =\frac{1}{1+\phi}\left\{3\left(\frac{x}{L}\right)^{2}-(4+\phi)\left(\frac{x}{L}\right)+(1+\phi)\right\} \\
\mathrm{N}_{9} & =\frac{-6}{(1+\phi) L}\left\{\left(\frac{x}{L}\right)^{2}-\left(\frac{x}{L}\right)\right\} \\
\mathrm{N}_{10} & =\frac{1}{1+\phi}\left\{3\left(\frac{x}{L}\right)^{2}-(2-\phi)\left(\frac{x}{L}\right)\right\}
\end{aligned}
$$

and $N_{i}^{*}=N_{i}\left(\phi^{*}\right), \phi$ and $\phi^{*}$ stiffness ratio due to flexion and shear:

$$
\begin{aligned}
\phi & =\frac{12}{L^{2}} \frac{\int_{S} E y^{2} d S}{k_{y} \int_{S} G d S} \\
\phi^{*} & =\frac{12}{L^{2}} \frac{\int_{S} E z^{2} d S}{k_{z} \int_{S} G d S}
\end{aligned}
$$




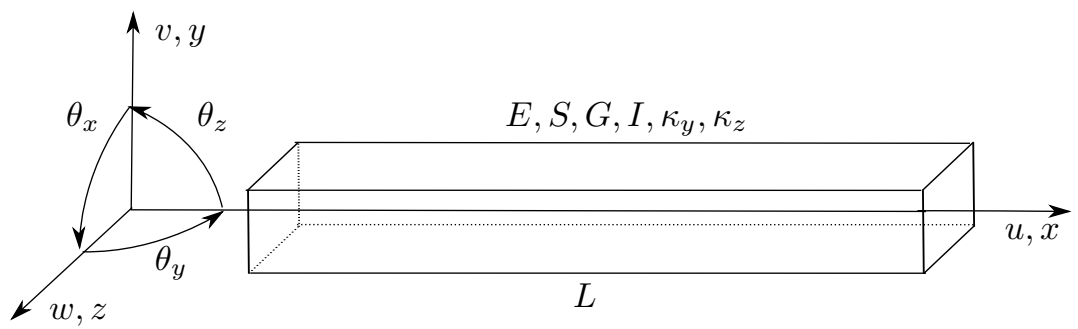

Figure 3. 3D Beam

The "generalised" displacements $\underline{\mathrm{U}}_{\mathrm{S}}$ (at the section level) are linked with the displacements at the nodes $U$ with the following equations:

$$
\begin{aligned}
& \underline{\mathrm{U}_{\mathrm{s}}}=\underline{\underline{N}} \underline{U} \\
& {\underline{\mathrm{U}_{\mathrm{s}}^{\mathrm{T}}}}^{\mathrm{T}}=\left\{\begin{array}{llllll}
u_{s}(x) & v_{s}(x) & w_{s}(x) & \theta_{s x}(x) & \theta_{s y}(x) & \theta_{s z}(x)
\end{array}\right\} \\
& \underline{\mathrm{U}}^{\mathrm{T}}=\left\{\begin{array}{llllllllllll}
u_{1} & v_{1} & w_{1} & \theta_{x 1} & \theta_{y 1} & \theta_{z 1} & u_{2} & v_{2} & w_{2} & \theta_{x 2} & \theta_{y 2} & \theta_{z 2}
\end{array}\right\}
\end{aligned}
$$

The section "generalized" stresses and strains are finally calculated by numerical integration, according to the equations provided in (Guedes et al., 1994).

The above interpolations functions depend on the materials properties and are calculated only once, during the first step. Introducing internal degrees of freedom in the formulation of the beam and adequate higher order interpolation functions (independent on the material properties) one can find the interpolation functions of Equations [4] and [5] through classical static condensation (Caillerie et al., n.d.).

In order to solve the torsion problem for a plane section composed of several materials, a warping-conduction analogy method is used (Proix et al., 2000), (Mazars et al., 2006). The problem of the calculation of the warping function $\varphi(y, z)$ for a section made up of several elastic materials (shear modulus $G_{i}$ ) is transformed into a 2D conduction problem in a plate made up of several materials (thermal conductivity $\left.\lambda_{i}\right)$. The equivalent conduction problem takes the following form (with $T(y, z)$ the temperature function):

$$
\Delta T(y, z)=0
$$


By applying the correct boundary conditions, the problem can be solved with any finite element code able to solve thermal conduction problems (Mazars et al., 2006).

\section{SSI macro-element}

The macro-element concept was applied for the first time in geomechanics in (Nova et al., 1991). It consists in condensing all nonlinearities into a finite domain and works with generalized variables (forces and displacements) that allow simulating the behaviour of shallow foundations in a simplified way. The macro-element developed in (Grange, 2008), (Grange et al., 2008a), (Grange et al., 2008b), (Grange et al., 2009) is inspired from (Crémer et al., 2001) and (Crémer et al., 2002) and it reproduces the behaviour of a 3D shallow foundation of circular, rectangular or strip shape, submitted to cyclic or dynamic loadings. It takes into account the plasticity of the soil and the uplift of the foundation. A brief outline of the formulation of the macro-element follows:

The associated generalized variables (displacement and force vectors) are dimensionless. They are defined hereafter (for any $a, a^{\prime}$ defines the corresponding dimensionless variable): vertical force $V^{\prime}$, horizontal forces $H_{x}^{\prime}, H_{y}^{\prime}$ and moments $M_{x}^{\prime}, M_{y}^{\prime}$, but also the corresponding displacements, vertical settlement $u_{z}^{\prime}$, horizontal displacements $u_{x}^{\prime}, u_{y}^{\prime}$ and rotations $\theta_{x}^{\prime}, \theta_{y}^{\prime}$. Torque moment $\left(M_{z}^{\prime}\right)$ is not taken into account (Figure 4).

(a)

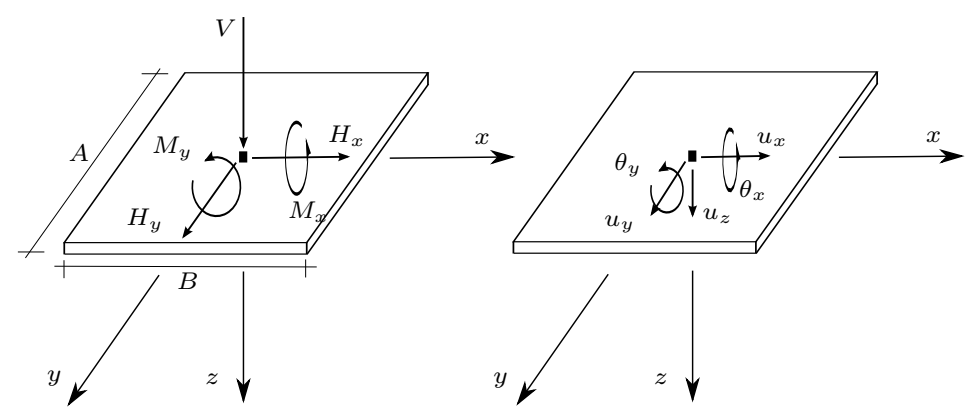

Figure 4. Generalised variables: (a) forces and (b) displacements for a rectangular foundation

The elastic part of the constitutive law is defined as $\underline{\mathbf{F}}=\underline{\underline{\mathbf{K}}}^{\mathbf{e l}} \underline{\mathbf{u}}^{\mathrm{el}}$, where the displacement $\underline{\mathbf{u}}^{\mathbf{e l}}$ and force vectors $\underline{\mathbf{F}}$ are dimensionless. The elastic stiffness matrix $\underline{\underline{\mathbf{K}}}^{\mathbf{e l}}$ is calculated using the real part of the static impedances. It is considered diagonal, i.e. there is not coupling between the different directions of the loading.

The failure criterion for the plasticity mechanism is defined for an overturning mechanism with uplift (Salençon et al., 1995), (Pecker, 1997). The adaptation in 3D is 
done by adding the two terms related with the horizontal force and moment according to the other axis and assuming axial symmetry. One finally obtains the following 5D surface, see Figure 5.

$$
\begin{array}{r}
f_{c}(\underline{\mathbf{F}}, \underline{\tau}, \rho, \gamma) \equiv\left(\frac{H_{x}^{\prime}}{\rho a V^{\prime c}\left(\gamma-V^{\prime}\right)^{d}}-\frac{\alpha_{1}}{\rho}\right)^{2}+\left(\frac{M_{y}^{\prime}}{\rho b V^{\prime e}\left(\gamma-V^{\prime}\right)^{f}}-\frac{\alpha_{2}}{\rho}\right)^{2} \\
+\left(\frac{H_{y}^{\prime}}{\rho a V^{\prime c}\left(\gamma-V^{\prime}\right)^{d}}-\frac{\alpha_{3}}{\rho}\right)^{2}+\left(\frac{M_{x}^{\prime}}{\rho b V^{\prime e}\left(\gamma-V^{\prime}\right)^{f}}-\frac{\alpha_{4}}{\rho}\right)^{2}-1=0
\end{array}
$$
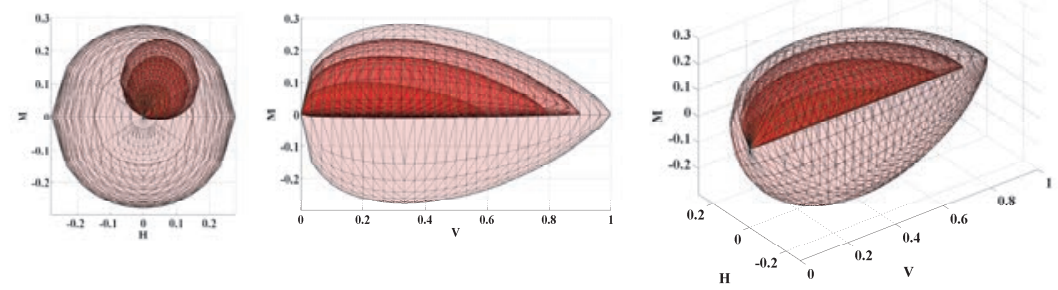

Figure 5. Evolution of the loading surfaces and failure criterion

The coefficients $a, b$ define the size of the surface in the planes $\left(H^{\prime}-M^{\prime}\right) . c$, $d, e$ and $f$ define the parabolic shape of the surface in the planes $\left(V^{\prime}-M^{\prime}\right)$ and $\left(V^{\prime}-H^{\prime}\right)$. Theses parameters can be fitted to different experimental results found in the literature. $\boldsymbol{\tau}=\left[\alpha_{1}, \alpha_{2}, \alpha_{3}, \alpha_{4}\right]$ is the kinematics hardening vector composed of 4 kinematics hardening variables and $\rho$ the isotropic hardening variable. The variable $\gamma$ is chosen to parametrize the second intersection point of the loading surface with the $V^{\prime}$ axis and its evolution along the $V^{\prime}$ axis. The evolutions of the hardening variables are obtained considering experimental results and numerical simulations (Crémer et al., 2001) of foundations under cyclic loadings.

The failure criterion is given by Equation [11] considering $\left(\alpha_{1}, \alpha_{2}, \alpha_{3}, \alpha_{4}, \rho, \gamma\right)=$ $(0,0,0,0,1,1)$. The flow rule used is associated in the $\left(H_{x}^{\prime}, M_{y}^{\prime}, H_{y}^{\prime}, M_{x}^{\prime}\right)$ hyperplane and non associated in the $\left(H_{x}^{\prime}, V^{\prime}\right),\left(M_{y}^{\prime}, V^{\prime}\right),\left(H_{y}^{\prime}, V^{\prime}\right),\left(M_{x}^{\prime}, V^{\prime}\right)$ planes.

Uplift behaviour is also treated according to the classical plasticity theory following the $M-\theta$ relationship proposed in (Crémer et al., 2001). For further details see (Grange, 2008). 


\section{Case studies}

\subsection{Modeling of the SAFE specimens}

\subsubsection{Description of the tests}

Within the SAFE research project, 13 squat reinforced concrete walls have been tested pseudodynamically (PSD test method) at the Joint Research Center of the European Commission at ISPRA in Italy (Pegon et al., 1998b) and (Pegon et al., 1998a). The specimens were very squat (slenderness 0.46 ) and the rotation of their upper part was restrained during the tests to ensure a high level of shear. The results of the numerical simulation of the T5 and T12 specimens using the ERC modelling strategy follow.

REMARK.- T5 and T12 had the same geometric characteristics, the only differences were the reinforcement ratio and the normal stress at the base (i.e. T12 had a much more important normal stress and a smaller reinforcement ratio).

\subsubsection{Numerical results}

Details about the concrete and steel meshes are provided in Figure 6. The chosen angle $\theta$ is calibrated from the experimental results $\theta=41,6^{\circ}$ for T5 and $\theta=30,1^{\circ}$ for T12). The flanges of the shear walls are described using multi-layered Bernoulli beam elements to account for bending. The width of these beam elements equals the actual length of the flange. Four stiff beam elements, the rotation of which is not allowed, simulate the top slab. Vertical displacement is free and the walls are fixed at the base. Concrete is simulated using a uniaxial damage mechanics law (La Borderie, 1991), (La Borderie, 2003) and steel with a classical uniaxial plasticity law with hardening.

Comparison of the experimental with the numerical results in Figure 7 shows that the ERC modelling strategy is able to reproduce the non linear behaviour of very squat $\mathrm{RC}$ walls in terms of global forces/displacements.

To study the influence of the angle $\theta$, a sensitivity analysis is presented in Figure 8 . For normally reinforced concrete structures (e.g. T5 specimen), the results of the simulation do not change significantly with the angle. A value between $35^{\circ}$ and $45^{\circ}$ correctly reproduces the global behaviour. However, for lightly reinforced concrete structures with an important normal stress (e.g. T12 specimen), the correct values of the angle are found significantly reduced (between $30^{\circ}$ and $33^{\circ}$ ).

Simulations of the SAFE campaign with the Rotating Angle Softened Truss Model (RA-STM, (Hsu, 1996)) are presented in Figure 9. As the RA-STM is based on experimental results where the rotation of the tested specimens was free, it underestimates the strength of the T5 and T12 specimens. The ERC model seems more adequate, at least for the examples studied here, as it can reproduce the behaviour of squat walls with or without rotation. In Figure 9 we present a comparison between the RA-STM 
and the ERC model, considering this time for the latter the top slabs free to rotate. The influence of the boundary conditions is apparent.

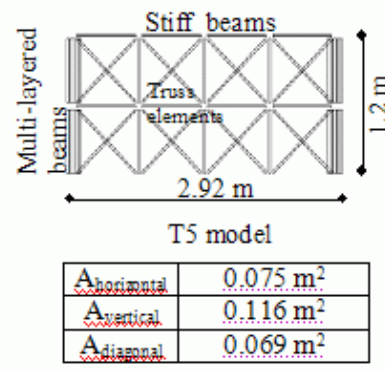

(a)

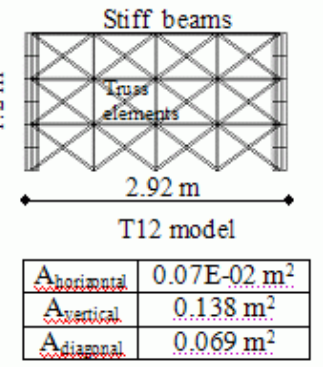

(b)

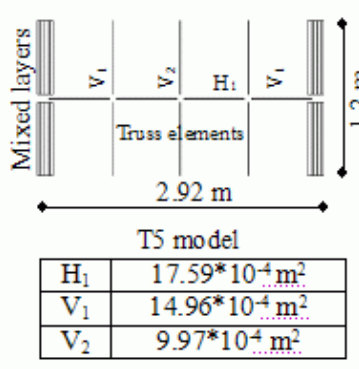

(c)

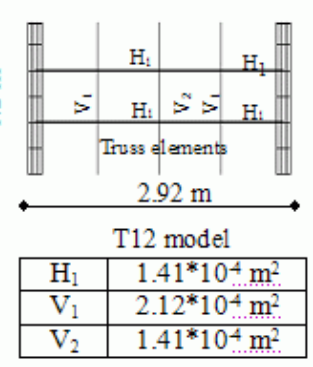

(d)

Figure 6. ERC model, meshes: concrete (a) and steel mesh (c) for T5, concrete (b) and steel mesh (d) for T12 specimens

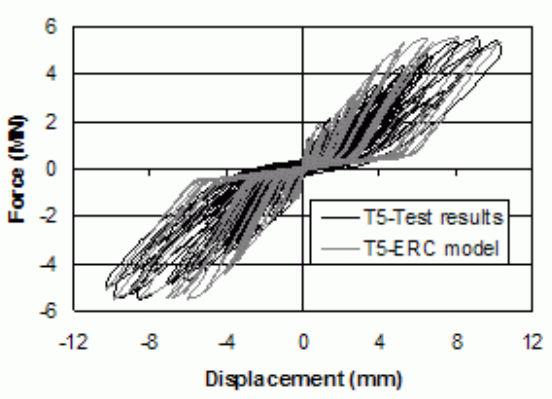

(a)

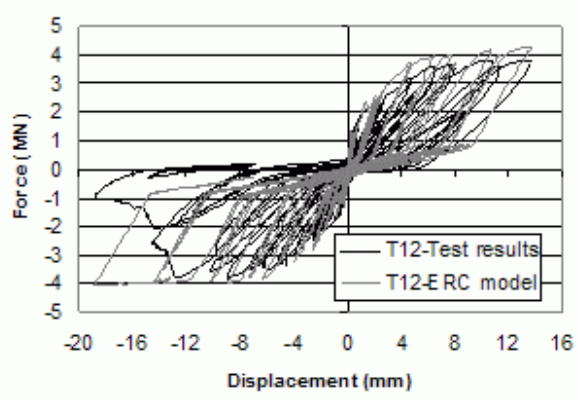

(b)

Figure 7. ERC model, numerical results: (a) T5 and (b) T12 specimens 

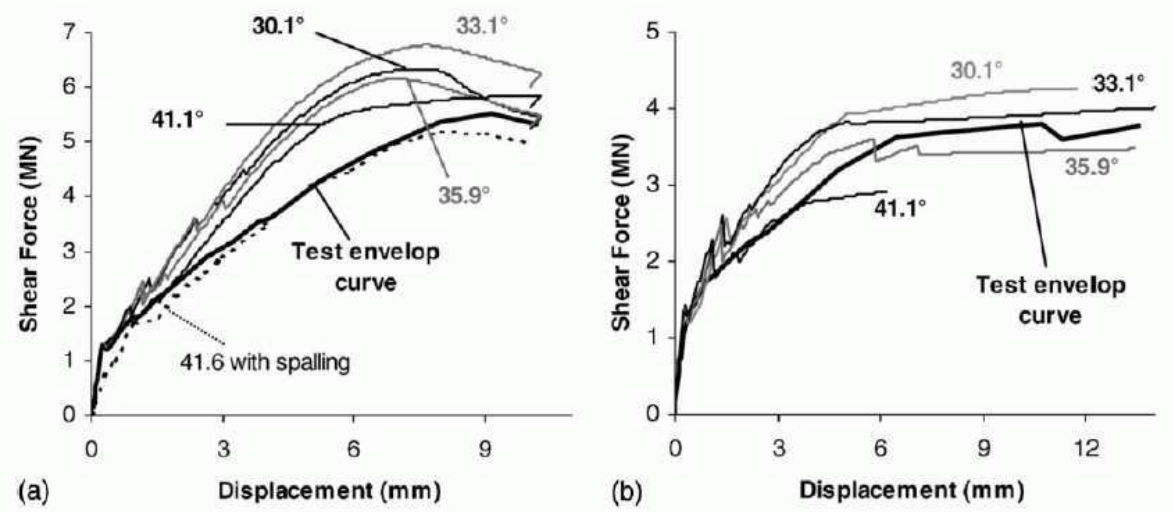

Figure 8. ERC model, monotonic simulations with various angles compared to the test envelope curve: (a) T5 and (b) T12 specimens
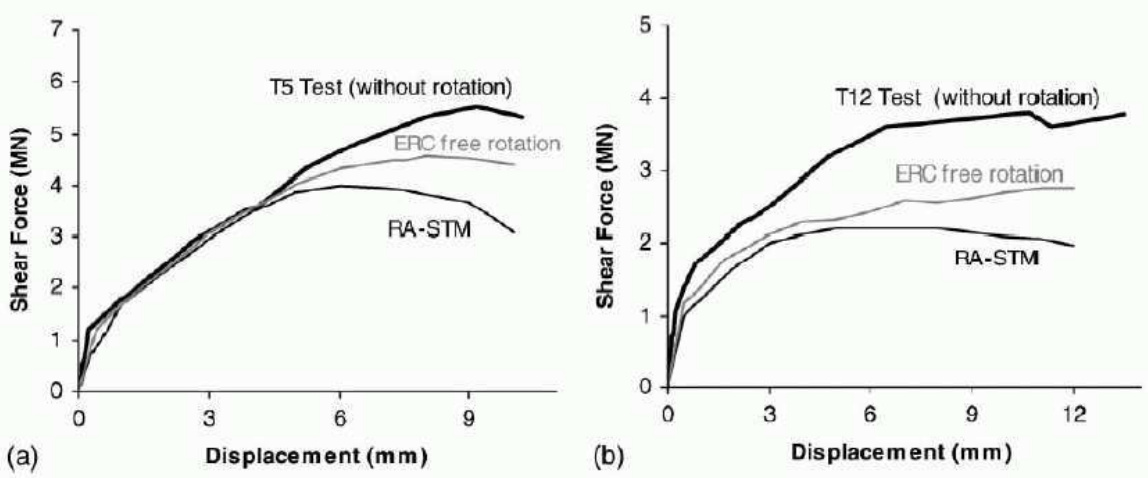

Figure 9. Simulation with RA-STM and simulation with ERC assuming the rotation of the top slab free

\subsection{Modelling SSI on a RC Viaduct}

\subsubsection{Description of the tests}

A $\frac{1}{2.5}$ scaled viaduct was recently tested pseudo-dynamically in ELSA (JRC Ispra), (Pinto et al., 1996). The geometrical characteristics of the viaduct are presented in Figure 10. 


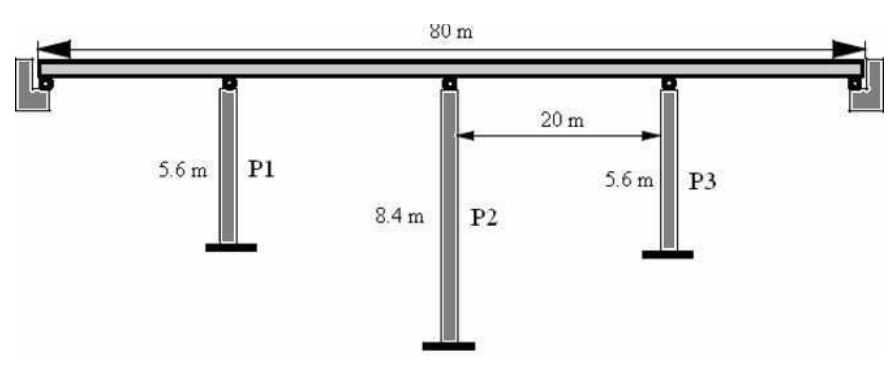

Figure 10. Viaduct - SSI: plan view of the tested viaduct in Ispra, (scale $\frac{1}{2.5}$ )

\subsubsection{Numerical results}

A model using Timoshenko multifiber beams and concentrated masses is chosen to reproduce the structure (Figure 11). Six beam elements are used for the piles P1 and P3 and nine elements for the pile P2. The mesh is refined at the base of the piles where damage tends to be important. 40 concrete fibers and 80 steel fibers (representing the reinforcement bars at their actual position) are used in each section. Details of the model are provided in (Grange et al., 2010). Concrete is simulated using a uniaxial damage mechanics law (La Borderie, 1991), (La Borderie, 2003) and steel with the classical Menegoto Pinto model (Menegoto et al., 1973).The desk being from prestressed concrete, its behaviour is assumed linear and it is discretised using linear beam elements. The loading is applied according to the $z$ axis. Calculations are made with FEDEASLab, a finite element MATLAB toolbox (Filippou et al., 2004).

Rectangular shallow foundations are numerically introduced at the base of each pile in two different ways, via macro-elements or linear springs. The dimensions of the foundations are: $L_{z}=4.2 \mathrm{~m}, L_{y}=2.1 \mathrm{~m}$. The stiffness of the springs is such that they accumulate the same energy as the non-linear SSI macro-element. A class C soil is considered according to the Eurocode 8 classification. Its characteristics are given in Table 1.

Table 1. Viaduct - SSI: Characteristics of the class C soil

\begin{tabular}{cllll}
\hline Soil & $\begin{array}{l}\text { Shear } \\
\text { modulus } G_{0} \\
\text { velocity } V_{s}\end{array}$ & $\begin{array}{l}\text { cohesion c } \\
\text { and friction } \\
\text { angle } \phi\end{array}$ & $\begin{array}{l}\text { Stiffness and } \\
\text { damping }\end{array}$ & $\begin{array}{l}\text { ultimate } \\
\text { bearing } \\
\text { stress } q_{\text {max }}\end{array}$ \\
\hline Class C & $V_{s}=150 \mathrm{~m} / \mathrm{s}$ & $c_{u}=150 \mathrm{kPa}$ & $K_{\theta \theta}=1112.5 \mathrm{MNm} / \mathrm{rad}$ & $q=1.1 \mathrm{MPa}$ \\
soil & $G_{0}=45 \mathrm{MPa}$ & $\phi_{u}=0$ & $K_{z z}=298.68 \mathrm{MN} / \mathrm{m}$ & \\
& & & $K_{h h}=244.36 \mathrm{MN} / \mathrm{m}$ & \\
& & $C_{\theta \theta}=4.34 \mathrm{MNms} / \mathrm{rad}$ & \\
& & $C_{z z}=1.17 \mathrm{MN} / \mathrm{m}$ & \\
& & $C_{h h}=1.00 \mathrm{MN} / \mathrm{m}$ & \\
\hline
\end{tabular}




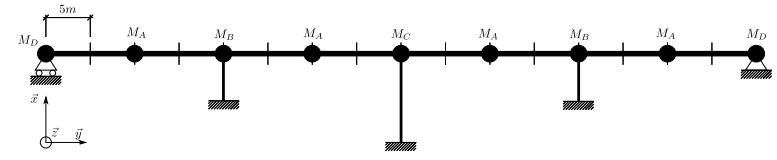

Figure 11. Viaduct - SSI: model using multifiber beam elements and concentrated masses
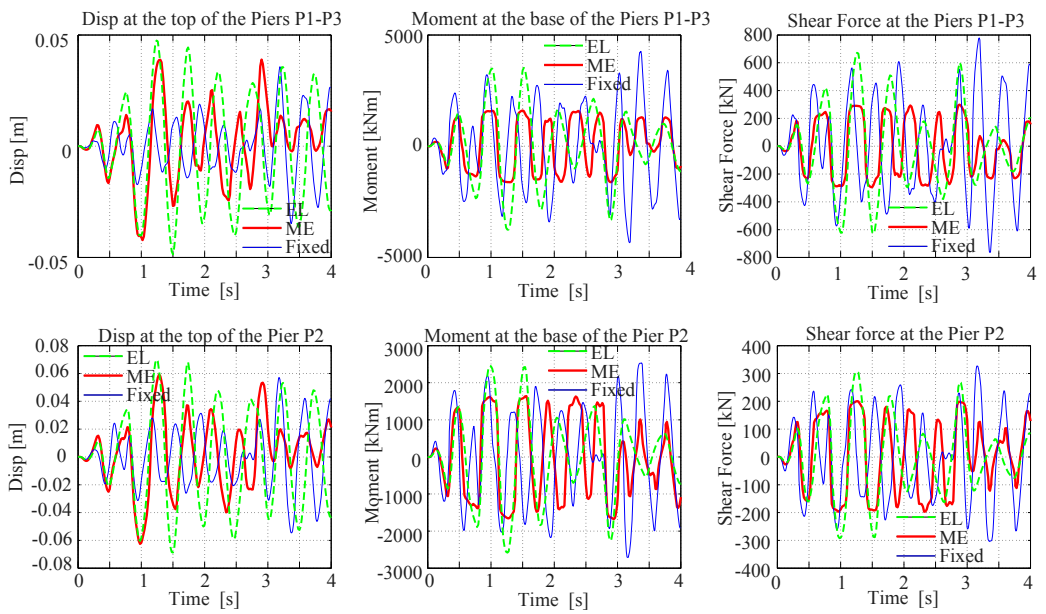

Figure 12. Viaduct - SSI: comparisons of the displacements, moments, shear forces for a class $C$ soil

Numerical results are presented in Figure 12. Three types of boundary conditions are considered: linear springs (EL), macro-element (ME) and embedded (Fixed). Displacements are strongly amplified, multiplied by 3 or 4 , for the case of the structure resting on the macro-element and on the linear elastic springs respectively. Differences are however more pronounced for the internal forces at the base of the piers (moments and shear forces). In fact, loads on the structure are significantly reduced for the case of the macro-element, due to the bearing moment and force capacity that are reached into the soil. Results obtained with the elastic linear springs have not such limits and can be similar to the ones found for the fixed piers. 


\section{Conclusions}

Different simplified modelling strategies for a variety of engineering problems are presented in this paper. The proposed tools are easy to use, not computational demanding and provide good results in terms of global variables. Although they also contain information on local variables, validation using experimental data or complex non linear models is necessary, especially when important levels of damage are expected. In this paper, numerical simulations are compared with experimental results, part of National but also International research programs (see also (Nguyen $e t$ al., 2006), (Kotronis et al., 2005b), (Bisch et al., 2007), (Ile et al., 2008), (Desprez et al., 2009)). Our current work is focused on finding methods to predict localisation phenomena in concrete structures ((Kotronis, 2008), (Kotronis et al., 2008)).

Acknowledgements

The authors are grateful for the financial support of the European Contracts ICONS (Innovative seismic design COncepts for New and existing Structures) of the TMR network (Training and Mobility of Researchers) and LESSLOSS (Risk Mitigation for Earthquakes and Landslides of the Sixth Framework Programme, Project No.: GOCECT-2003-505488), http://www.lessloss.org.

\section{References}

Bisch P., Coin A., Ile N., Kotronis P., Mazars J., Nguyen X., Reynouard J., “ Performance sismique des structures à murs banchés : le programme européen ECOLEADER", Revue Européenne de Génie Civil, vol. 11, n 3, p. 311-353, 2007.

Caillerie D., Kotronis P., Cybulski R., “ An improved Timoshenko beam finite element with internal degrees of freedom", Computer and Structures, n.d. in preparation.

Crémer C., Pecker A., Davenne L., " Cyclic macro-element for soil-structure interaction: material and geometrical non-linearities", International Journal for Numerical and Analytical Methods in Geomechanics, vol. 25, n 13, p. 1257-1284, 2001.

Crémer C., Pecker A., Davenne L., " Modelling of nonlinear dynamic behaviour of a shallow strip foundation with macro-element", Journal of Earthquake Engineering, vol. 6, $\mathrm{n}^{\circ} 2$, p. 175-211, 2002.

Desprez C., Kotronis P., Mazars J., Paultre P., B-Trudeau M., “ Retrofitting reinforced concrete structures with FRP: Numerical simulations using multifiber beam elements", COMPDYN 2009, 2nd International Conference on Computational Methods in Structural Dynamics and Earthquake Engineering, Island of Rhodes, 22-24 June, 2009.

Filippou F., Constantinides M., FedeasLab Getting Started Guide And Simulations Examples, Report, Dpt of civil and Env. Engng. UC Berkeley, 2004.

Friedman Z., Kosmatka J., “ An improved two-node Timoshenko beam finite element”, Computers and Structures, vol. 47, n 3 , p. 473-481, 1993. 
Grange S., Modélisation simplifiée 3D de l'interaction sol-structure: application au génie parasismique, Thèse de doctorat, http://tel.archives-ouvertes.fr/tel-00306842/fr, INP Grenoble, 2008 .

Grange S., Botrugno L., Kotronis P., Tamagnini C., " On the influence of soil structure interaction on a reinforced concrete bridge", Earthquake Engineering and Structural Dynamics, 2010. (accepted for publication).

Grange S., Kotronis P., Mazars J., “ A macro-element for a circular foundation to simulate 3D soil-structure interaction”, International Journal for Numerical and Analytical Methods in Geomechanics, vol. 32, n 10, p. 1205-1227, 2008a.

Grange S., Kotronis P., Mazars J., “ A macro-element for a shallow foundation to simulate SoilStructure Interaction considering uplift”, C. R. Mécanique, vol. 336, n 11-12, p. 856-862, $2008 b$.

Grange S., Kotronis P., Mazars J., “A macro-element to simulate 3D soil-structure interaction considering plasticity and uplift”, International Journal of Solids and Structures, vol. 46, $\mathrm{n}^{\circ} 20$, p. 3651-3663, 2009.

Guedes J., Pégon P., Pinto A., A fibre Timoshenko beam element in CASTEM 2000, Special publication nr. i.94.31, i-21020, J.R.C., Ispra, Italy, 1994.

Hrennikoff A., " Solution of problems of elasticity by the framework method", Journal of Applied Mechanicsp. A169-75, 1941.

Hsu T., " Toward a unified nomenclature for reinforced concrete theory", Journal of Structural Engineering, ASCE, vol. 122, p. 275-283, 1996.

Ile N., Nguyen X., Kotronis P., Mazars J., Reynouard J., “ Shaking table tests of lightly RC walls: Numerical simulations", Journal of Earthquake Engineering, vol. 12, n 6, p. 849878, 2008.

Kotronis P., Cisaillement dynamique de murs en béton armé. Modèles simplifiés 2D et 3D, Thèse de doctorat, ENS Cachan, 2000. http://tel.archives-ouvertes.fr/tel-00074469/fr.

Kotronis P., Stratégies de modélisation de structures en béton soumises à des chargements sévères, Habilitation à diriger des recherches, Université Joseph Fourier, 2008. http://tel.archives-ouvertes.fr/tel-00350461/fr.

Kotronis P., Al Holo S., Bésuelle P., Chambon R., " Shear softening and localization: Modelling the evolution of the width of the shear zone", Acta Geotechnica, vol. 3, n² 2, p. 85-97, 2008.

Kotronis P., Davenne L., Mazars J., “ Poutre 3D multifibre Timoshenko pour la modélisation des structures en béton armé soumises à des chargements sévères”, Revue Française de Génie Civil, vol. 8, n²-3, p. 329-343, 2004.

Kotronis P., Mazars J., " Simplified modelling strategies to simulate the dynamic behaviour of r/c walls", Journal of Earthquake Engineering, vol. 9, n 2, p. 285-306, 2005a.

Kotronis P., Mazars J., Davenne L., “ The equivalent reinforced concrete model for simulating the behavior of shear walls under dynamic loading", Engineering Fracture Mechanics, vol. 70, $\mathrm{n}^{\circ}$ 7-8, p. 1085-1097, 2003.

Kotronis P., Ragueneau F., Mazars J., “ A simplified modelling strategy for R/C walls satisfying PS92 and EC8 design”, Engineering Structures, vol. 27, n 8, p. 1197-1208, 2005b.

La Borderie C., Phénomènes unilatéraux dans un matériau endommageable: modélisation et application à l'analyse des structures en béton, Thèse de doctorat, Université Paris 6, 1991. 
La Borderie C., Stratégies et modèles de calculs pour les structures en béton, Habilitation à diriger des recherches, Université de Pau et des Pays de l'Adour, 2003.

Mazars J., Kotronis P., Davenne L., "A new modelling strategy for the behaviour of shear walls under dynamic loading”, Earthquake Engineering and Structural Dynamics, vol. 31, $\mathrm{n}^{\circ} 4$, p. 937-954, 2002.

Mazars J., Kotronis P., Ragueneau F., Casaux G., "Using multifiber beams to account for shear and torsion. Applications to concrete structural elements", Computer Methods in Applied Mechanics and Engineering, vol. 195, $\mathrm{n}^{\circ}$ 52, p. 7264-7281, 2006.

Menegoto M., Pinto P., "Method of analysis of cyclically loaded reinforced concrete plane frames including changes in geometry and non-elastic behaviour of elements under combined normal force and bending", IABSE Symposium on resistance and ultimate deformability of structures acted on by well-defined repeated loads, final report, Lisbon, 1973.

Nguyen N., Mazars J., Kotronis P., "Modélisation simplifiée 3D du comportement dynamique de structures en béton armé", Revue européenne de génie civil, vol. 10, n 3, p. 361-374, 2006.

Nova R., Montrasio L., "Settlements of shallow foundations on sand", Géotechnique, vol. 41, $\mathrm{n}^{\circ} 2$, p. 243-256, 1991.

Pecker A., Analytical formulae for the seismic bearing capacity of shallow strip foundations. In Seismic Behavior of Ground and Geotechnical Structures, E. Pinto, S. Balkema, p. 261-268, Rotterdam, 1997.

Pegon P., Magonette G., Molina F., Verzeletti G., Dyngeland T., Negro P., Programme SAFE: Rapport du test T12, Technical report, JRC, Ispra, Italy, 1998a.

Pegon P., Magonette G., Molina F., Verzeletti G., Dyngeland T., Negro P., Programme SAFE: Rapport du test T5, Technical report, JRC, Ispra, Italy, 1998 b.

Pinto A., Verzeletti G., Pegon P., Magonette G., Negro P., Guedes J., Pseudo Dynamic Testing of Large-Scale R/C Bridges, Hmc grant holder, report eur. 16378 en, JRC, Ispra, Italy, 1996.

Proix J., Laurent N., Hemon P., Bertrand G., Eléments mécaniques à fibre moyenne, Document: R3.08.03, Calcul des caractéristiques d'une poutre de section transversale quelconque, Code aster, manuel de référence, fascicule r3.08, EDF, 2000.

Salençon J., Pecker A., "Ultimate bearing capacity of shallow foundations under inclined and eccentric loads. Part II: purely cohesive soil without tensile strength", European Journal of Mechanics, A/Solids, vol. 14, n 3, p. 377-396, 1995. 